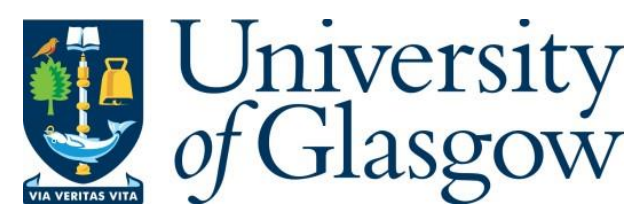

Whyte, W. and Lytsy, B. (2019) Ultraclean air systems and the claim that laminar airflow systems fail to prevent deep infections after total joint arthroplasty. Journal of Hospital Infection, 103(1), e9-e15.

There may be differences between this version and the published version. You are advised to consult the publisher's version if you wish to cite from it.

http://eprints.gla.ac.uk/186843/

Deposited on: 7 January 2020

Enlighten - Research publications by members of the University of Glasgow http://eprints.gla.ac.uk 


\title{
Ultraclean air systems and the claim that laminar airflow systems fails to prevent deep infections after total joint arthroplasty
}

\author{
W. Whyte, University of Glasgow, Glasgow, UK \\ B. Lytsy, Uppsala University Hospital (Akademiska Sjukhuset), Uppsala, Sweden
}

\section{Summary}

The WHO published guidelines in 2016 for preventing surgical site infections. The guidelines contained a conditional recommendation that laminar airflow (LAF) ventilation systems should not be used to reduce the risk of infection after total joint arthroplasty (TJA). This recommendation was largely based on a systematic review and meta-analysis of information from hospital infection surveillance registries. The recommendation contradicts information published in earlier major studies carried out by Charnley and the UK Medical Research Council (MRC).

The first aim of this article is to revisit and explain the MRC study, and reply to criticisms of it. The second aim is to suggest reasons why some recent studies have failed to demonstrate that ultra clean air (UCA) systems reduce deep joint infection after TJA.

It is concluded that if an UCA system establishes average airborne concentrations of microbe-carrying particles (MCPs) below $10 / \mathrm{m}^{3}$, and preferably below $1 / \mathrm{m}^{3}$, then deep joint infection after TJA will be lower than in conventionally ventilated operating theatres.

Key words: Ultra clean air, LAF, total joint arthroplasty, surgical infections

\section{Introduction}

The WHO published guidelines in 2016 for the prevention of surgical site infections [1], with a conditional recommendation that LAF ventilation systems should not be used to reduce the risk of infection at the site of operation after TJA. This recommendation was largely based on the work of Bischoff et al [2] who carried out a meta-analysis of data from studies that compared LAF systems with conventionally ventilated operating theatres. This recommendation has been controversial $[3,4]$ and it is an aim of this article to challenge the WHO recommendation.

The failure of various studies to agree with the MRC results has been partly ascribed to poor organisation of the MRC study, and the other aim of this article is to refute these criticisms.

\section{Terms used in this article}

The term 'colony forming unit (CFU)' is often used to describe airborne micro-organisms but this description is more an acknowledgement that a micro-organism is viable than a 
description of a micro-organism in the air of an operating theatre. Micro-organisms are not normally found as unicellular organisms in the air of operating theatres, as they are almost entirely dispersed from personnel on skin cells [5]. Microbe-carrying particle (MCP) is a more apt descriptive and used in this article.

Two types of ventilation systems are used worldwide in operating theatres. The most common type is known as 'conventionally ventilated', where about 20 air changes per hour of filtered air is supplied through ceiling inlets to mix, dilute, and remove airborne contamination out through low-level air extracts. The other type is unidirectional airflow (UDAF), which has a bank of air filters in the ceiling that are approximately $3 \mathrm{~m} \times 3 \mathrm{~m}$. The filters supply a steady flow of air in parallel streams, which sweeps away MCPs from the sterile field. UDAF systems supply considerably more air than conventional and, if correctly designed, reduce the MCP concentration by about 100 times (see Table 1).

UDAF systems are often called laminar airflow (LAF) systems. However, it is scientifically incorrect to use this term, as the air velocity is too high to be 'laminar', and the airflow is turbulent [3]. The name used throughout the cleanroom industry is 'unidirectional airflow' and this term is used in this article. However, where papers use the term, it is quoted as 'LAF'. As the airflow in both the UDAF and conventional system is turbulent, it is best not to use 'turbulent' only when describing the conventional system. It is therefore called 'conventionally ventilated operation theatre' in this article.

The term 'ultra clean air (UCA)' is used in this article to describe airborne conditions that give an average concentration of MCPs at the surgical wound of $\leq 10 / \mathrm{m}^{3}$, and preferably $\leq 1 / \mathrm{m}^{3}$. An UCA system normally consists of a well-designed UDAF ventilation system, with the surgical team wearing occlusive clothing that reduces their airborne dispersion.

\section{Charnley's research}

Professor Sir John Charnley carried out pioneering work on replacing diseased hip joints with artificial ones. These investigations have been described by Charnley [6] and Lidwell [7]. Charnley's earliest hip replacements were carried out in an operating theatre with high counts of airborne MCPs (around $800 / \mathrm{m}^{3}$ ) and he encountered unacceptable rates of deep joint infection in excess of $7 \%$.

Charnley thought it likely that a cemented prosthesis created a unique situation where only a few microbes could cause deep joint infections, and surgical asepsis had to be exceptional. This was confirmed in a canine model by Petty et al [8]. It was also found during the MRC study [9] that a small dose of Staphylococcus aureus, possibly only one bacterium, was sufficient to initiate an infection in TJA.

Charnley improved his operating theatre in stages by improving the ventilation and design of the surgical enclosure. He also introduced 'total-body exhaust gowns' which are one-piece surgical gowns made from impervious cotton fabric and worn with helmets coupled to a flexible exhaust tube. The exhaust tube removes MCPs dispersed under the gown, and substantially reduces the concentration of MCPs in the sterile field. Charnley found that the 
stage-by-stage reduction of airborne MCPs was accompanied by parallel reductions in the deep joint infection rate, and when he concluded his investigations the airborne concentration was about $1 / \mathrm{m}^{3}$ and the infection rate just over $0.5 \%$.

However, Charnley's conclusions were not universally accepted and to prove, or disprove, his conclusions, the Medical Research Council (MRC) in the UK, set up a multi-centred, prospective, and randomised study of UCA systems.

\section{MRC multi-centre study of UCA systems}

\section{Organisation of MRC study}

The MRC study was carried out between 1974 and 1979, and run by a steering committee of Drs OM Lidwell (chair), EJL Lowbury, R Blowers, and W Whyte. It also included statisticians, SJ Stanley and D Lowe, from the MRC Biostatistical Unit.

Initial statistical calculations showed that to demonstrate with a $90 \%$ probability at a $95 \%$ confidence level, a difference between a control group with a $2 \%$ incidence of infection, and a test group where the incidence would drop to $1 \%$, about 2500 operations were required in each group. As the MRC study compared a control with two test groups, 7500 TJA operations were required. To obtain sufficient information, 19 hospitals in the UK and Sweden were included, and 8136 TJA operations were studied.

Contrary to what has been written [2], the MRC established a relationship between airborne concentrations of MCPs and deep joint infections. To establish this relationship, conventionally ventilated operating theatres and a variety of clean air systems were studied (see Table 1). Some doubt has also been expressed [2] as to the effectiveness of the ventilation of the conventionally ventilated operating theatres included in the study, but to be included they had to be designed to the requirements in the Report of the MRC and Department of Health and Social Security in the UK [10]. This required positivepressurisation of the operating theatre with a filtered air supply of around 20 air changes per hour, as well as other requirements. These still remain current UK requirements [11].

The MRC study was a prospective study with patients being allotted at random to conventionally ventilated operating theatres or UCA systems. This was carried out by drawing a sealed envelope each week after the operating list had been prepared.

Research nurses recorded patient and other information, which was sent to the MRC Biostatistical Unit for checking and analysis. The first paper [12] was published in 1982 and followed by further articles [9, 13, 14, 15, 16] and a review [17]. These articles were also been reviewed by Dr Lidwell [18]. Unfortunately, there has often been a failure to consider and understand all of the information published and, because of this, the MRC results are now reviewed. 


\section{Airborne MCP counts}

The airborne concentrations of MCPs during surgery were measured close to the wound, using the methods explained elsewhere [13]. The effect of ventilation systems and surgical clothing is shown in Table 1.

Table 1 Airborne MCP concentrations per $\mathrm{m}^{3}$

\begin{tabular}{|c|c|c|}
\hline \multirow[t]{2}{*}{ Ventilation system } & \multicolumn{2}{|c|}{ Clothing type } \\
\hline & Conventional $^{1}$ & $\begin{array}{l}\text { Total body } \\
\text { exhaust } \\
\text { gowns }\end{array}$ \\
\hline Conventionally ventilated & 164 & 51 \\
\hline Allander $^{2}$ & 49 & 14 \\
\hline Horizontal UDAF & 22 & 1 \\
\hline Vertical UDAF, without walls & 10 & - \\
\hline Vertical UDAF, with walls & 2 & 0.4 \\
\hline Isolator $^{3}$ & 0.5 & - \\
\hline
\end{tabular}

1: Conventional clothing was the standard type of cotton shirt, trousers, and gown.

2: The Allander system is a low velocity downward airflow system with air curtains round the air supply perimeter, and described elsewhere [19].

3: The Isolator system is described elsewhere [20].

\section{Wound washout counts}

Wounds were washed by surgeons to determine the number of micro-organisms in the wound prior to closing. This was carried out with a large syringe and $150 \mathrm{ml}$ of sterile, quarter-strength, Ringers solution, which was collected in a kidney dish placed at the lower edge of the wound. The number of micro-organisms in the washout liquid was determined by methods described elsewhere [13].

Wound washes were carried out at the same time as the measurement of airborne concentrations of MCPs. By analysing the wound washout counts at different airborne concentrations, it was calculated that in conventionally ventilated operating theatres most of wound contamination came from air. Initial experiments showed that $98 \%$ of microbes in the patient's wounds came from the air [21], and the MRC study found that it was greater than $95 \%$ [13].

\section{Deep joint infection rates}

To obtain a large proportion of deep joint infections, the TJA operations were followed for an average of 2.5 years, with a maximum of 5 years. Deep joint infections were identified by the criteria explained by Lidwell et al $[12,15]$ but were only considered to be deep infections after a re-operation had confirmed it.

The infection rates after surgery in various types of UCA systems were compared to conventionally ventilated operating theatres and these rates have been reported in an article [12] that should be consulted to obtain the magnitudes and statistical significance of the various comparisons. The overall effect of all the UCA systems showed that the infection rate was significantly reduced from $1.5 \%$ in the control series to $0.6 \%(p<0.001)$ in the UCA 
series. Prophylactic antibiotics were found to affect the infection rates. Table 2 shows the effects of both UCA systems and prophylactic antibiotics on infection rates.

Table 2 Deep joint infection rates after TJA

\begin{tabular}{|l|l|l|}
\hline $\begin{array}{l}\text { Type of ventilation } \\
\text { system }\end{array}$ & $\begin{array}{l}\text { No antibiotics } \\
\text { given }\end{array}$ & Antibiotics given \\
\hline $\begin{array}{l}\text { Conventional airflow } \\
\text { with conventional } \\
\text { clothing }\end{array}$ & $39 / 1161(3.4 \%)$ & $24 / 2968(0.8 \%)$ \\
\hline $\begin{array}{l}\text { UDAF systems with } \\
\text { conventional clothing }\end{array}$ & $8 / 516(1.6 \%)$ & $9 / 1279(0.7 \%)$ \\
\hline $\begin{array}{l}\text { UDAF systems with } \\
\text { total-body exhaust } \\
\text { gowns, plus isolators }\end{array}$ & $5 / 544(0.9 \%)$ & $1 / 1584(0.06 \%)$ \\
\hline
\end{tabular}

It can be seen in Table 2 that the infection rate in the group of patients who were not given prophylactic antibiotics was significantly reduced from $3.4 \%$ to $1.6 \%$ when UDAF systems with conventional clothing were used instead of conventionally ventilated operating theatres. A greater reduction from $3.4 \%$ to $0.9 \%$ was obtained when total-body exhaust gowns or isolators were used. Both these reductions were statistically significant $(\mathrm{p}<0.05)$.

In the group of patients who received prophylactic antibiotics, the joint infection rate was reduced from $0.8 \%$ to $7 \%$ when UDAF systems with conventional clothing were used instead of conventional ventilation; this reduction was not large enough to give a statistically significant difference $(\mathrm{p}>0.1)$. However, when total body exhaust gowns or isolators were used, the infection rate dropped significantly to $0.06 \%(\mathrm{p}<0.05)$. The results given in Table 2 are consistent with clean air and prophylactic antibiotics combining independently and multiplicatively to reduce deep joint infection. The use of UCA in place of conventional ventilation gives a two-fold reduction and, when combined with special clothing, a 4.5 reduction. Both these reductions are further reduced by four-fold when antibiotics are used. These conclusions were similar to a French study [22] that was carried out at a similar time to the MRC study, which found that antibiotics gave a 3.5 reduction, and UCA systems halved the infection rates.

Surgeons were free to use their preferred practice of antibiotic use, and about two thirds of the patients received prophylactic antibiotics during the MRC study. The experimental design of the MRC study has been criticised for not controlling antibiotic use [2]. This criticism would have been legitimate if the study had been set up to measure the effect of prophylactic antibiotics on joint infection, but it was not. As Dr Lidwell explained [18], the use of antibiotics did not invalidate the assessment of the effect of UCA systems, as when antibiotics were given, or not, this was done equally in the conventionally ventilated control group and in the UCA operating theatres test group.

As well as carrying a simple comparison of the rates of infection given in Table 2, a wide variety of risk factors that might affect the infection rates were analysed by sequential 
multiple logistic regression analysis [15]. This analysis was used to investigate the importance of risk factors but also to minimise potential confounding by risk factors, such as prophylactic antibiotics. The multiple regression analysis included twenty-three possible risk factors, and statistically significant regression coefficients were obtained that gave the magnitude of the effect of each factor on deep joint infection. The reciprocal of the regression coefficient gave an 'incidence ratio'. This allowed a direct comparison to be made between the multiple regression results and the simple ratios obtained from the infection rates given in Table 2. The incidence ratios from the multiple regression analysis gave a ratio of 1.82 when UCA systems were compared to conventional ventilation, and a ratio of 4.55 when body exhaust gowns and isolators were used; both these ratios were statistically significant ( $>0.05$ ). These ratios are very close to the magnitude of the simple ratios given in Table 2, and confirm the effect of UCA systems and that there was no appreciable imbalance between the control and UCA groups. The suggestion that the results of the MRC study were biased by uncontrolled use of antibiotics is, therefore, incorrect.

It has been written [2] that the MRC study did not consider the relation between the airborne concentrations of MCPs and deep infection. This is incorrect, and by grouping operations with similar concentrations of MCPs, the relationship of airborne concentration of MCPs to deep infection rates was obtained (Figure 1) [13]. Each point on the line is an average of the results from 6 to 9 hospitals.

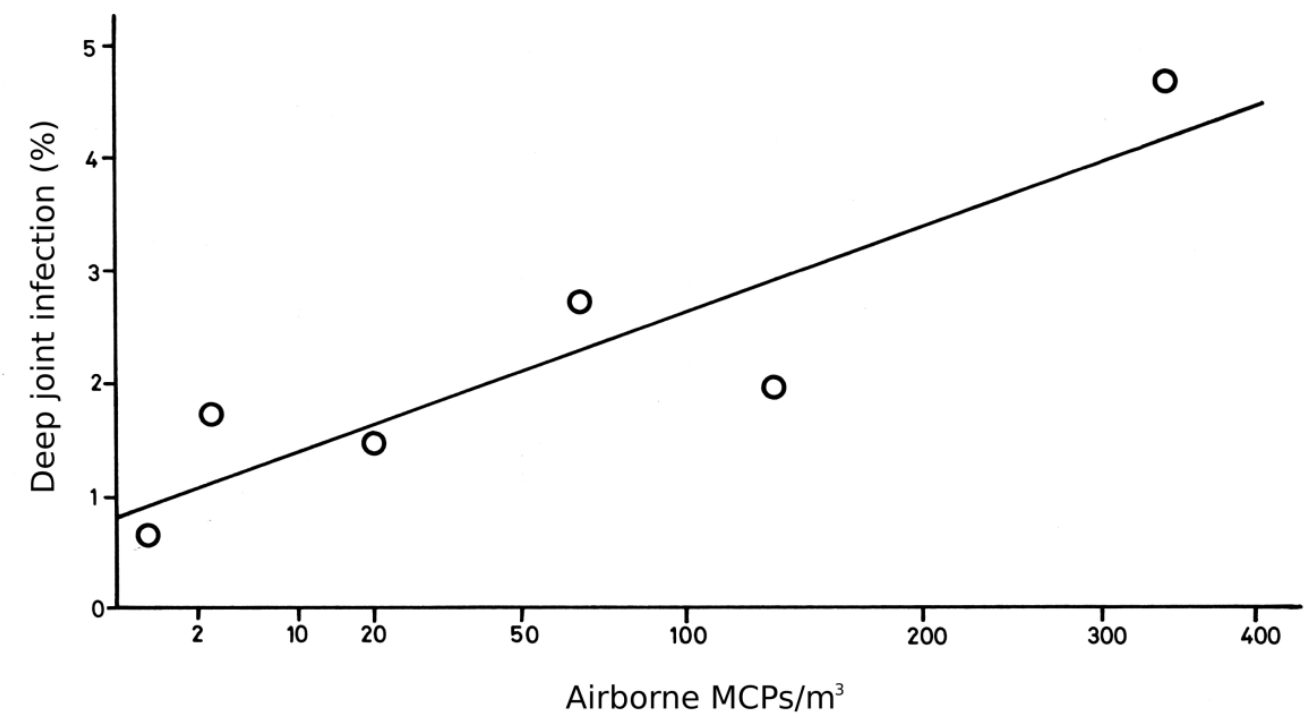

Figure 1 Relationship between deep joint infection and concentration of airborne MCPs

It can be seen in Figure 1 that there was a strong correlation between the MCP airborne concentration and joint infection and, at a MCP concentration of $\leq 1 / \mathrm{m}^{3}$, infection caused by airborne contamination is close to a minimum. However, this desirable concentration of $\leq 1 / \mathrm{m}^{3}$ is difficult to achieve, except in well-designed UCA systems with the surgical team wearing special occlusive clothing. This is not always possible, but if the average value is set at $10 / \mathrm{m}^{3}$, then a worthwhile reduction in deep infection rate to about half of that found in 
conventionally-ventilated operating theatres is likely to be achieved. The MRC steering committee recommended [14] that an average airborne concentration of $10 / \mathrm{m}^{3}$ should not be exceeded in UCA systems but that a greater benefit would result from an airborne concentration of $1 / \mathrm{m}^{3}$. A concentration of $10 / \mathrm{m}^{3}$ was adopted by the countries that participated in the MRC study [11,23].

Associated research investigations were supported by the MRC and carried out during the main study into the design of UCA systems and effectiveness of surgical clothing. These studies have been reviewed [24, 25] and shown the following:

(a) Vertical UDAF systems are more effective than horizontal.

(b) Some means of constraining the supply air from ceiling filters, such as solid or flexible walls that may be full or partial, or air curtains, is needed to ensure that air moves unidirectionally to the surgical field. This is especially important if the air supply is hotter and more buoyant than ambient room air, or the air exhausts are poorly positioned and cause short circuiting of supply air. These requirements should also help to minimise the penetration of airborne contamination external to the clean zone.

c) Obstructions, and air rising from heat sources, should be minimised to prevent disruption of the UDAF.

c) To ensure an effective UCA system and obtain low airborne concentrations of MCPs, a minimum air velocity of $\geq 0.35 \mathrm{~m} / \mathrm{s}$ is required for UDAF systems with full walls, and $\geq 0.38 \mathrm{~m} / \mathrm{s}$ with partial walls. These velocities will ensure that unidirectional flow is quickly reinstated after being disturbed by movements of the surgical team.

(d) A sufficiently large clean area should be provided to protect not only the wound, but items exposed on surgical trolleys.

(e) Special occlusive clothing is required to minimise airborne dispersion of MCPs from the surgical team, and a concentration of $10 / \mathrm{m}^{3}$ is unlikely to be achieved with conventional cotton garments.

These studies showed that a surgical enclosure and total body exhaust system similar to that advocated by Charnley will achieved airborne concentrations of $1 / \mathrm{m}^{3}$, but it was difficult to achieve this with other designs, and some designs will not achieve an average concentration of $10 / \mathrm{m}^{3}$. The consequence of this, with respect to the failure of 'LAF' systems to show a reduction in deep infections after TJA, is discussed in the next section.

\section{More recent studies on the effectiveness of LAF systems}

Over the last decade or so, studies have been published that compare infection rates from conventionally ventilated operating theatres with so-called 'LAF' systems. Bischoff et al [2] identified twelve of these studies [26-37] and carried out a meta-analysis of their results. Four studies [38-41] were excluded because they did not meet the criteria explained in their paper. Also, any study carried out before 1990 was excluded, and therefore the studies of Charnley and the MRC were not included. Bischoff et al concluded that 'LAF' systems failed to show a reduction in wound infection. However, such claims must be examined critically. 
An important deficiency of the studies analysed by Bischoff et al is their failure to report airborne concentrations of MCPs and to correlate MCP concentrations to infection rates. As discussed in the previous section, designing an efficient UDAF systems and selecting occlusive clothing needs specialised knowledge [24, 25] and, without this, UCA systems will often fail to provide acceptable airborne concentrations. For example, a study carried out in 28 operating theatres in 14 hospitals [42] showed that about half the air samples from systems considered to be UCA, failed to achieve a MCP concentration of $\leq 10 / \mathrm{m}^{3}$ and UCA systems with small filter ceilings had higher airborne concentrations than conventionally ventilated operating theatres. It should, therefore, not be assumed that because a ventilation system is called 'laminar airflow' it will achieve average MCP counts lower than $10 / \mathrm{m}^{3}$ and preferably $1 / \mathrm{m}^{3}$, or will be superior to a conventionally ventilated operating theatre. Without confirmation of the airborne concentration of MCPs, any claims about the ineffectiveness of UCA systems must be doubted.

Bischoff's analysis was dominated by retrospective studies that used information on wound infections from surveillance registries [26-33]. This data could introduce a bias between infection rates obtained from operating theatre ventilation systems in different hospitals, when (a) different preventative measures were used to reduce the infection rate, (b) different antibiotic usage practices were used, and (c) there were different types of patients, surgical teams, and procedures. Another bias could be introduced if superficial infections were registered, as these were shown not to be significantly influenced by airborne conditions [15]. Also, TJA patients should be followed up over an extended period of time, preferably several years, to ensure that a reasonably high proportion of deep infections are included [16]. It was accepted by both Bischoff et al and the WHO that their recommendation was based on 'very low quality evidence'. It is clear that the conclusions from Bischoff et al's study provide a much weaker evidence base than obtained from a multi-centre prospective randomized study, like the MRC study.

Bischoff et al's study divided their meta-analysis into TJA operations, and other types of operations. The orthopaedic group were mainly registry studies and, with the exception of one study which showed a benefit of UCA systems with total knee replacements [33], no advantage was shown by UCA systems. Two studies were non-registry, and one study showed the benefit of the 'LAF' system [35] and the other showed a benefit in total knee replacement but not hip replacement [26]. The studies of other types of operations were dominated by a one registry study [30] that showed no benefit, but the other two non-registry studies showed a benefit of 'LAF' systems [34, 35].

Four studies were excluded from Bischoff's analysis. One was excluded because behavioural changes were made in addition to the use of a 'LAF' [38] and, in the other study, the doors in the 'LAF' theatre automatically closed, but in the conventionally ventilated theatres the doors were generally kept open [39]. However, it is of interest to find that there was a drop in infection rates associated with 'LAF' systems in both these studies. Two other studies were excluded because total body exhaust gowns were used in addition to the 'LAF' system but, as previously explained; occlusive clothing is an integral part of UCA systems. One of these studies showed a reduction in wound infection [40] but the other did not [41]. 
It is interesting to consider that had the registry studies been excluded on the basis of their very low quality evidence, and only non-registry studies analysed along with the MRC and Charnley's studies, Bischoff et al's conclusion would most likely have been reversed.

\section{Discussion}

The first part of this article deals with criticisms of the MRC study of UCA systems. It was shown that contrary to what has been reported [2], surgical operations and prophylactic antibiotics were properly randomised between ventilation conditions, and there was a correlation between the concentration of airborne MCPs and infection rates. It was also explained that the ventilation systems of conventional operating theatres included in the MRC study were the type still installed.

The MRC study was discussed in terms of (a) the substantial variation of the airborne concentration of MCPs in various designs of UCA systems, (b) the fact that over $95 \%$ of the micro-organisms in the wound, at closure, came from the air in a conventionally ventilated operating theatre, (c) the establishment of the relationship between deep infection rate and airborne concentrations of MCPs, (d) the reasons for a preferred concentration of $1 / \mathrm{m}^{3}$, and acceptable concentration of $10 / \mathrm{m}^{3}$ as a standard for UCA systems. Also described was a multivariate analysis that showed no appreciable bias in the study caused by an imbalance of variables that might affect the results, such as antibiotic use. Further information was also given about associated studies [24, 25] that investigated the design UCA systems, and occlusive clothing, needed to minimise the airborne concentration of MCPs.

The second part of this article considers the WHO Guidelines [1], and Bischoff et al's systematic review and meta-analysis [2], which mainly analysed results from surveillance registries and failed to find a reduction of infection rates by using 'LAF' systems. The quality of information analysed was accepted by the WHO and Bischoff et al as 'very low quality' and this was discussed. The results of the Charnley and MRC studies were excluded because they were carried out before 1990. However, the information obtained by these two studies, is fundamental information that does not change through time. It was also suggested that if the registry studies were excluded from a meta-analysis, and other relevant studies included, Bischoff's conclusion was likely to be reversed.

Information was lacking in the studies analysed by Bischcoff et al about the type of UCA system or surgical clothing worn, and, more importantly, whether an acceptable airborne concentration of MCPs of $10 / \mathrm{m}^{3}$, or a desirable $1 / \mathrm{m}^{3}$, was achieved. As shown by the study of airborne conditions in operating theatres [42], it was likely that many of the ventilation systems reported as 'LAF' systems did not reach $10 / \mathrm{m}^{3}$, and some may have been no better than conventionally ventilated operating theatres. It is suggested that any future studies into the effect of clean air, must assess the performance of ventilation systems and clothing by measuring the microbial cleanliness of the air. This is normally carried out by air samplers, but a simple alternative method is to expose a Petri dish (or dishes) during the operation [43].

In addition to the evidence obtained by Charnley and the MRC study, consideration should be made of the strong evidence that shows airborne MCPs cause wound infections. It has been shown that outbreaks of infection produced by unusual types of Staphylococcus 
aureus could only have been transmitted by the airborne route by a person in the operating theatre $[44,45]$.

\section{Conclusions}

The evidence-base for the use of UCA during TJA that was obtained by Charnley was confirmed by the MRC study. The results of the MRC study remain valid, solid and convincing. Criticisms of the MRC study have been addressed in this article and shown to be invalid. The MRC study showed that airborne concentrations of $10 \mathrm{MCP} / \mathrm{m}^{3}$, and preferable 1 $\mathrm{MCP} / \mathrm{m}^{3}$, are required for TJA to prevent deep joint infections.

The WHO conditional recommendation that 'LAF' technology is not necessary to prevent deep joint infection after TJA is judged to be supported by very poor quality evidence. The evidence base for that recommendation lacks information about the performance of the UCA systems studied, and was largely based on surveillance registries which provided very low quality information.

Deep joint infection after TJA has profound consequences to patients and the health service. Within the perspective of the emerging problem of antibiotic resistance, all transfers of micro-organisms into an operation wound should be minimised to ensure that antibiotics have the greatest chance of success. In the case of TJA, where the dominant route of infection has clearly been shown to be airborne, UCA systems should be used. It is our opinion that prevention is better than cure.

\section{References}

1 Global guidelines for the prevention of surgical site infection. World Health Organization. World Health Organization, Geneva, Switzerland, 2016.

2 Bischoff P, Kubilay NZ, Allegranzi, Egger M and Gastmeier P. Effect of laminar airflow ventilation on surgical site infections: a systematic review and meta-analysis. Lancet Infect Dis 2017; 17: 553-61.

3 Thomas AM and Simmons MJ. The effectiveness of ultra-clean air operating theatres in the prevention of deep infection in joint arthroplasty. Bone Joint J 2018. 100-B: 126469.

4 Jutte PC, Traversari RAAL and Walenkamp GHIM. Laminar flow: the better choice in orthopaedic implants. Lancet Infect Dis 2017; 17: 695-6.

5 Whyte W and Hejab M. Particle and microbial airborne dispersion from people. European Journal of Parenteral and Pharmaceutical Sciences 2007; 12: 39-46.

6 Charnley J. Low friction arthroplasty of the hip: theory and practice. Springer, Berlin 1972.

7 Lidwell OM. Sir John Charnley, Surgeon (1911-82): the control of infection after total joint replacement. J Hosp Infect 1993; 23: 51-5.

8 Petty W, Spanier S, Schuster J and Silverthorne C. The influence of skeletal implants on the incidence of infection: experiments in a canine model. J Bone Joint Surg Am 1985; 67A: $1235-44$. 
9 Lidwell OM, Lowbury EJL, Whyte W, Blowers R, Stanley SJ and Lowe D. Bacteria isolated from deep joint sepsis after operation for total hip or knee replacement and the sources of the infections with Staphylococcus aureus. J Hosp Infect 1983; 4: 192-9.

10 Report of committee on ventilation in operation suites. MRC and DHSS, London, UK. 1972.

11 Health Technical Memorandum 03-01. Specialised ventilation for healthcare premises. Part A - Design and installation. Department of Health, UK, 2007.

12 Lidwell OM, Lowbury EJL, Whyte W, Blowers R, Stanley SJ and. Lowe D. Effect of ultraclean air in operating rooms on deep sepsis in the joint after total hip or knee replacement: a randomised study. Br Med J 1982; 285: 101-4.

13 Lidwell OM, Lowbury EJL, Whyte W, Blowers R, Stanley SJ and Lowe D. Airborne contamination of wounds in joint replacement operations: the relationship to sepsis rates. J Hosp Infect 1983; 4: 111-31.

14 Whyte W, Lidwell OM, Lowbury EJL and Blowers R. Suggested bacteriological standards for air in ultraclean operating rooms. J Hosp Infect 1983; 4: 133-9.

15 Lidwell OM, Lowbury EJL, Whyte W, Blowers R, Stanley SJ, and Lowe D. Infection and sepsis after operations for total hip or knee-joint replacement: Influence of ultraclean air, prophylactic antibiotics and other factors. J Hyg Camb 1984; 93: 505-29.

16 Lidwell OM, Lowbury EJL, Whyte W, Blowers R, Stanley SJ, and Lowe D. Extended follow-up of patients suspected of having sepsis in the joint after total joint replacement. J Hyg Camb 1985; 95: 655-64.

17 Lidwell OM, Elson R.A, Lowbury EJL, Whyte W, Blowers R, Stanley SJ and Lowe D. Ultraclean air and antibiotics for prevention of postoperative infection. Acta Orthop Scand 1987; 58: 4-13.

18 Lidwell OM. Air, antibiotics and sepsis in replacement joints. J Hosp Infect 1988; 11 (Supplement C): 18-40.

19 Allander C. System for ventilating clean rooms. United States Patent 33803691966.

20 Trexler P C. An isolator system for the maintenance of aseptic environments. Lancet 1973; 1(7794): 91-3.

21 Whyte W, Hodgson R and Tinkler J. The importance of airborne bacterial contamination of wounds. J Hosp Infect 1982; 3: 123-35.

22 Hill C, Flamant R, Mazas F and Evrard J. Prophylactic cefazolin versus placebo in total hip replacement. Lancet 1981; 1(8224): 795-6.

23 Technical specification SIS-TS 39: Microbiological cleanliness in the operating room Guidance and fundamental requirements. Swedish Standards Institute, Stockholm, Sweden, 2015.

24 Whyte W. The effect of mechanical ventilation and clothing on airborne microbes and wound sepsis in hospital operating rooms, part 1. Clean Air Cont Rev 2015; 22: 4-11. Available at : http://eprints.gla.ac.uk/105802/1/105802.pdf

25 Whyte $\mathrm{W}$. The effect of mechanical ventilation and clothing on airborne microbes and wound sepsis in hospital operating rooms, part 2. Clean Air Cont Rev 2015; 23: 4-12. Available at: http://eprints.gla.ac.uk/108159/1/108159.pdf 
26 Brandt C, Hott U, Sohr D, Daschner F, Gastmeier P and Ruden H. Operating room ventilation with laminar airflow shows no protective effect on the surgical site infection rate in orthopaedic and abdominal surgery. Ann Surg 2008; 248: 695-700.

27 Dale H, Hallan G, Espehaug B, Havelin LI, Engesaeter LB. Increasing risk of revision due to deep infection after hip arthroplasty. Acta Orthop 2009; 80: 639-45.

28 Namba R, Inacio MC, Paxton EW. Risk factors associated with deep surgical site infection in 30,491 primary total hip replacements. J Bone Joint Surgery Am 2013; 95 : 775-82.

29 Namba R, Inacio MC, Paxton EW. Risk factors associated with deep surgical infection site infections after primary total knee arthroplasty - an analysis of 56,216 knees. J Bone Joint Surg Am 2013; 95: 775-82.

30 Breier AC, Brandt C, Sohr D, Geffers C, Gastmeier P. Laminar flow ceiling size: no impact on infection rates following hip and knee prosthesis. Infect Control Hosp Epidemiology 2011; 32: 1097-102.

31 Hooper GJ, Rothwell AG, Frampton C, Wyatt MC. Does the use of laminar flow and space suites reduce early deep infection after total hip and knee replacement? The tenyear results of the New Zealand Joint Registry. J Bone Joint Surg Br 2011 ; 93: 85-90

32 Pederson A, Svendsson JE, Johnsen SP, Riis A, Overgaard S. Risk factors for revision due to infection after primary total hip arthroplasty. A population based study of 80756 primary procedures in the Danish Hip Arthroplasty Registry. Acta Orthop 2010; 81: 54247.

33 Song KM, Kim ES, Kim YK, et al. Differences in the risk factors for surgical site infection between total hip arthroplasty and total knee arthroplasty in the Korean Nosocomial Infections Surveillance System (KONIS). Infect Control Hosp Epidemiol 2012; 33: 1086-93.

34 Miner AL, Losina E, Katz JN, Fossel AH, Platt R. Deep infection after total knee replacement: impact of laminar airflow systems and body exhaust systems in the modern operating room. Infect Control Hosp Epidemiol 2007; 28: 222-6.

35 Kakwani RG, Yohannan D and Wahab KHA The effect of laminar air flow on the results of Austin-Moore hemiarthroplasty. Injury 2007; 38: 820-3.

36 Jeong SJ, Ann HW, Kim JK et al. Incidence and risk factors for surgical site infection after gastric surgery: a multicentre prospective cohort study. Infect Chemother 2013; 45: 422-30.

37 Bosanquent DC, Jones, Gill N, Jarvis P and Lewis MH. Laminar flow reduces case of surgical site infections in vascular patients. Ann R Coll Surg Engl 2013; 95: 15-19.

38 Kobben BA, van Horn JR, van der Mei HC, Busscher HJ. Evaluation of measures to decrease intra-operative bacterial contamination in orthopaedic implant surgery. J Hosp Infect 2006; 62: 174-80.

39 Yavuz SS, Bicer Y, Yapice N and Kalaca S, Aydin OO, Camur, G, Kocak F and Aykac Z. Analysis of risk factors for sternal surgical site infection emphasizing the appropriate ventilation of the operating theaters. Infect Control Hosp Epidemiol 2006; 27: 958-63.

40 Greunberg MF, Campaner GL, Sola CA, Ortolan EG. Ultraclean air for prevention of postoperative infection after posterior spinal fusion with instrumentation: a comparison 
between surgeries performed with and without a vertical exponential filtered air-flow system. Spine 2004; 29: 2330-34.

41 Van Griethuysen AJA, Spies-van Rooijen NH and Hoogenboom-Verdegaal AMM. Surveillance of wound infections and a new theatre; unexpected lack of improvement. J Hosp Infect 1996; 34: 99-106.

42 Agodi A, et al. Operating theatre ventilation systems and microbial air contamination in total joint replacement surgery: results of the GISIO-ISChIA study. J Hosp Infect 2015; 90: 213-9.

43 Harp JH. A clinical test to measure airborne microbial contamination on the sterile field during total joint replacement - method, reference values and pilot study. J Bone Joint Surg - Open Access. Available at: https://journals.lww.com/jbjsoa/Fulltext/2018/09000/A_Clinical_Test to_Measure_Airb orne Microbial.10.aspx

44 Ayliffe GAJ and Collins BJ. Wound infections from a disperser of an unusual strain of Staphylococcus aureus. J Clin Path 1967; 20: 195-8.

45 Payne R. Severe outbreak of surgical sepsis due to Staphylococcus aureus of unusual type and origin. Br Med J 1967; 4(5570): 17-20. 